\title{
Duality of Enterprise and Stakeholders on Flexibility Front
}

\author{
Sushil
}

Received: 14 July 2014/ Accepted: 14 July 2014/Published online: 27 July 2014

(C) Global Institute of Flexible Systems Management 2014

There is inherent duality between the enterprise and its stakeholders. An enterprise is a separate legal entity than its stakeholders. The stakeholders for any enterprise could be owners, investors, shareholders, employees, customers, partners, suppliers, distributors, government, regulators, society, and so on. The stakeholders, in general, expect flexibility from the side of the enterprise. They usually aspire that the enterprise should be responsive to their needs. For example, customers desire that the enterprise should provide them with customized products, services and solutions that may fulfill their specific needs. Similarly, employees expect that the enterprise should provide them enough flexibility and freedom of choice. This includes flexibility in work-time, place of work, compensation, and so on. On similar lines, expectations of all the stakeholders for flexibility and responsiveness on the part of the enterprise can be delineated.

On the other hand, enterprise also demands flexibility from various stakeholders. It requires that investors should respond to its funding requirements with flexible terms and conditions. It also desires that employees should develop multiple skills and be able to handle the work assigned as per the changing requirements. Almost all the enterprises expect that the government should provide flexible policy options to suit their unique requirements.

It would be more rewarding, if both the enterprise and stakeholders work towards providing flexibility to each other rather than demanding it from the other side. If the stakeholders become responsive and enterprise provides a

\section{Sushil $(\square)$}

Department of Management Studies, Indian Institute of

Technology Delhi, Vishwakarma Bhawan, Shaheed Jeet Singh

Marg, New Delhi 110016, India

e-mail: profsushil@gmail.com; sushil@dms.iitd.ac.in framework of flexibility, it would be a win-win situation. If the enterprise becomes flexible at various levels of operations, organization and strategy, and the stakeholders become open and responsive at the same time, the whole value network and the ecosystem may be able to handle any uncertainty and change, thereby reaching to higher level of performance.

We can discuss the provisions of flexibility by enterprise to stakeholders and vice versa one by one. On one hand, enterprise can provide choices or options in products to customers; it can customize them to suit unique requirements and handle the customer requirements with speed and agility. The case of Dell's direct marketing model through e-commerce provided a framework for customers to give specifications required by them and, in turn, customized products could be delivered. The customers on the other hand, can be more aware and enlightened, clearly specify their needs, give feedback for improvement, and may even co-create value with the enterprise. Many technology based companies, such as automobiles and telecom, involve lead customers in their product development teams.

In the case of employees, the enterprise may create flexible work culture and adopt flexible work practices, such as flexi-time, flexi-place, work from home, train the employees to be multi-skilled, and so on. At the same time, employees can respond to changing needs of the enterprise by meeting urgent work requirements, adapting themselves as per the client requirements, be more open and give respect to others' ideas, and even willing to work with lower compensation in adverse monetary situation of the enterprise. This has recently been practiced in aviation industry in India, where employees agreed to work at lower salaries in times of adversity.

In case of partners, flexibility is to be extended from both the sides in terms of meeting the changing capacity 
requirements as per market fluctuations. Though there is always a contractual obligation from either side, in case of adverse situation of one partner the other one may extend a helping hand for forging a long-term relationship. A partner should be a partner in true sense rather than simply an outsourcing agency or vendor. The success of partners depends on the success of each other. In case of outsourcing industry, a visible change could be noted towards partnership model from the prevalent outsourcing model.

Another major flexibility relationship exists between the enterprise and the society. An enterprise gets business and various inputs from the society, and society, in turn, gets developed with high performing enterprises. The sustainability of both depends on each other. Enterprises should contribute to the societal change and upliftment, and the society is expected to reinforce the development of enterprises leading to overall progress. Adopting new technological solutions by the society would encourage enterprises to come up with more innovations in future. The case of Hindustan Unilever Limited (HUL) is worth noting in this regard that started doing business with the philosophy of "doing well by doing good". It can be observed that societal response to new technology in service sector; particularly in banking and travel has visibly created many innovative solutions.

Government-Business relationship (not nexus) is also of high importance for the whole economy. If the Government comes forward with more flexibility in its policies of creating new business, taxation etc., it will foster economic development. Similarly, business enterprises must respond to financial, societal and environmental challenges faced by the government and come proactively for solving the upcoming vital problems. The public-private partnership (PPP) model is a case in point of a win-win relationship, between government and private enterprises.

Thus, it is worth noting that both the enterprise and its stakeholders should proactively provide flexibility to the other side rather than only demanding flexibility from the other side. This is true in any relationship; providing flexibility creates a win-win situation, whereas demanding flexibility may, in general, result into a win-lose relationship. The enterprise and stakeholder interactions would result into a star model of performance (Sushil 2010). In this model, the performance of enterprise is related with the performance of key stakeholders, which would result into creation of a sustainable enterprise.

\section{Reference}

Sushil, (2010). Star Model of Sustainable Enterprise. Global Journal of Flexible Systems Management, 11(4), iii. 